\title{
La extensión de la
}

jurisprudencia: soportes constitucionales,

efectos y aspectos controversiales

\section{en su aplicación}

\author{
Mario Aguilera-Martin ${ }^{1}$ \\ JuAn Aponte-GonzÁlez ${ }^{2}$
}

\section{RESUMEN}

La constitucionalización del derecho ha hecho que la Administración tienda a ser más garantista en el amparo de los derechos de los ciudadanos. Ese impacto se ha consolidado con la expedición de la Ley 1437 de 2011 que, de manera novedosa, consagró entre sus finalidades la protección de los derechos y libertades de las personas e introdujo, entre otras, la figura de la extensión de la jurisprudencia, que permite a los ciudadanos acudir ante una autoridad administrativa para solicitar la extensión de los efectos de una sentencia de unificación que haya reconocido un derecho, acreditando los mismos supuestos

1 Abogado, Universidad Externado de Colombia, Bogotá, Colombia. Especialista en Derecho Administrativo, Universidad del Rosario, Bogotá, Colombia. Asesor y consultor en temas de derecho administrativo. Correo-e: m.alejandro.aguilera@hotmail.com

2 Abogado, Universidad Externado de Colombia, Bogotá, Colombia. Especialista en Derecho Administrativo, Universidad del Rosario, Bogotá, Colombia. Abogado de la Secretaría Distrital de Hábitat - Subdirección de Inspección, Vigilancia y Control de Vivienda, Bogotá, Colombia. Correo-e: jdag2908@gmail.com Fecha de recepción: 30 de noviembre de 2016. Fecha de modificación: 10 de marzo de 2017. Fecha de aceptación: 30 de mayo de 2017. Para citar el artículo: Aguilera-Martin, M., Aponte-GonZÁlezZ, J. "La extensión de la jurisprudencia: soportes constitucionales, efectos y aspectos controversiales sobre su aplicación", Revista digital de Derecho Administrativo, n. ${ }^{\circ} 18$, segundo semestre, Universidad Externado de Colombia, 2017, pp. 85-113. DOI: https://doi.org/10.18601/21452946.n18.06 
fácticos y jurídicos. El presente artículo pretende mostrar sus orígenes, elementos, efectos, y los aspectos controversiales que han surgido en su aplicación, a partir del análisis de casos resueltos por el Consejo de Estado.

Palabras clave: Constitucionalización, Estado social de derecho, Extensión de la jurisprudencia, Sentencia de unificación, Precedente jurisprudencial, Seguridad jurídica, Igualdad, Identidad fáctica, Identidad jurídica, Corte Constitucional, Consejo de Estado, Autoridad administrativa, Autonomía judicial, Vinculatoriedad del precedente.

\title{
The Extension of Jurisprudence: Constitutional Supports, Effects, and Controversial Aspects in its Application
}

\begin{abstract}
The constitutionalization of Law has led to an increase protection of citizen rights by the Public Administration. As means of a higher level of protection, Act 1437 of 2011 introduces the procedure of the 'extension of jurisprudence', which entitles citizens to request administrative agencies to apply to their individual case the same standard of protection that was awarded in a prior judicial decision, when that decision constitutes a unified precedent, and when both cases have identical legal and factual grounds. This article examines, with the aid of the jurisprudence of the Council of State, the origins, reach and controversial aspects surrounding this innovative legal procedure.
\end{abstract}

Keywords: Constitutionalization, Rule Of Law, Extension of Jurisprudence, Unified Judicial Precedent, Constitutional Court, Council of State, Administrative Agencies, Judicial Independence, Biding Precedent.

\section{PRESENTACIÓN}

El presente texto intenta estudiar los efectos de la extensión de la jurisprudencia, mostrando particularmente sus aspectos controversiales. Resaltamos dos: 1) Los efectos negativos de la posibilidad de las autoridades administrativas de apartarse del precedente de las altas cortes, y 2) Las consecuencias derivadas de la no inclusión, de las providencias de las altas cortes y de las sentencias de las cortes internacionales donde se haya establecido un precedente claro, como objeto del mecanismo de extensión de la jurisprudencia. Para desarrollar estos planteamientos hemos dividido el presente texto en varios aspectos: primero, presentamos los antecedentes de la figura en estudio. Luego, describimos los 
componentes de la extensión de la jurisprudencia, con base en su consagración legal. En tercer lugar, abordamos los asuntos problemáticos, y finalmente, mostramos algunos casos que concretan nuestros cuestionamientos.

\section{INTRODUCCIÓN}

En nuestro país la figura de la extensión de la jurisprudencia en el ámbito del derecho administrativo está claramente relacionada con la llamada "constitucionalización del derecho" ${ }^{\prime \prime}$. Este postulado cardinal, cada vez más en boga, del derecho administrativo considera que el estudio, interpretación y aplicación del ordenamiento jurídico de un país debe hacerse en función de la Constitución-como norma de normas-con el fin de lograr una verdadera materialización de los principios y valores en ella contenidos.

El fenómeno de la constitucionalización del derecho tiene como punto de partida y resulta ser consecuencia del tránsito del "Estado de derecho", donde el eje central del ordenamiento jurídico era la ley, al "Estado social de derecho", donde lo es la Constitución. El primero, fue obra de una reacción al Estado absolutista, caracterizado por el poder despótico del rey ("La ley soy yo"). Al instituirse el sometimiento a la "voluntad del pueblo" y al recogerse su mandato formalmente en leyes, estas se convierten en una herramienta civilizadora idónea para establecer una determinada forma de sociedad y de Estado. En consecuencia, al reconocerse la jerarquía de las normas y al acogerse el principio de legalidad, tanto los ciudadanos como el gobernante se encontrarían limitados por la voluntad de la ley 4 .

El "Estado social de derecho" por su parte, introduce una nueva lectura del derecho pues este es asumido desde la observancia estricta de la dignidad humana y la justicia social, replanteando el esquema del Estado de derecho liberal, cuyas bases se habían consagrado bajo la idea del gobierno de la ley como elemento indispensable para alcanzar la libertad (laissez faire, laissez passer), pero que traerían elevados costos para la igualdad como valor fundante en toda sociedad. Por tanto, es bajo este rótulo de "Estado social", consagrado

3 Acerca de este fenómeno las distintas posturas doctrinarias no han sido unánimes sobre su entendimiento, por lo cual recomendamos: JeAn PAul Velásquez GómeZ, La constitucionalización del juez administrativo en Colombia, Bogotá: Grupo Editorial Ibáñez, 2004, pp. 43-50. El autor, luego de analizar los diferentes enfoques que se le han dado al concepto, señala: "De conformidad con todo lo expuesto, podemos decir entonces que la constitucionalización es un fenómeno de 'invasión' o 'irradiación' de las normas constitucionales y los postulados del llamado Estado Constitucional y Democrático de Derecho en todas las ramas y especialidades del derecho, así como en las actividades que desarrolla el Estado en sus diversas manifestaciones (legislativa, judicial, gubernativa, administrativa, de control, etc. Inclusive en aquella que desarrollan los particulares)".

4 Camilo Velásquez Turbay, Derecho constitucional, Bogotá: Universidad Externado de Colombia, 2004, pp. 271-273. 
en nuestra Constitución de 1991 (art. 1), que el Estado se empodera como estructura garante y responsable de la realización efectiva de los principios y derechos constitucionales de los ciudadanos -como fin en sí mismo-, consolidando su función interventora, llevando los hilos de la economía y de esta forma trabajando en pro de los fines sociales y el bienestar general ${ }^{5}$. De ahí que se cree un catálogo amplio de derechos, especialmente frente a ciertos sectores "vulnerables" de la sociedad. Por ello pasan a ser centrales temas como el de los niños, las mujeres, los ancianos, los minusválidos, la vivienda digna, etc. ${ }^{6}$.

En palabras de la Corte Constitucional, el Estado colombiano se adecua a las nuevas exigencias con "la sujeción formal al derecho y una sujeción material del derecho a los contenidos sustanciales. El primer elemento es relativo a la validez, el segundo a la justicia"7.

Ahora bien, siendo esto conceptualmente muy enriquecedor para el ordenamiento jurídico de un Estado, y habiéndose consagrado desde 1991 en nuestra Constitución, es válido preguntarnos: cpor qué su influencia e impacto habían resultado ciertamente precarios en el derecho administrativo? Sin duda, esto pudo ser resultado de cierto letargo legislativo y de nuestra cultura jurídica, pues dentro de la Administración se ha percibido cierta renuencia al amparo efectivo de los derechos ciudadanos, a los que se considera más como contraparte. De todas maneras parece claro que sólo se empezó a hablar con mayor propiedad de la "constitucionalización del derecho administrativo" desde la expedición de la Ley 1437 de 2011.

5 Sobre el punto se precisa: "Colombia es un Estado de Derecho, y ello no es incompatible con la afirmación de ser un Estado Social de Derecho. La importante transformación introducida con la Constitución Política de 1991, que termina el proceso iniciado por la reforma constitucional de 1936, hacia el componente social, no determinó el abandono de los elementos que permiten afirmar que un Estado es de Derecho, pero lo complementó, lo moduló, lo dirigió hacia fines sociales": Andrés Fernando Ospina FernándeZ, "Presentación: la responsabilidad del Estado y el Estado de derecho en Colombia", en La responsabilidad extracontractual del Estado, Bogotá: Universidad Externado de Colombia, JuAN Carlos Henao y Andrés Fernando Ospina Garzón (eds.), 2015, p. 13.

6 Diego Younes Moreno, Derecho constitucional colombiano, Bogotá: Legis, 2014, pp. 59-66

7 Corte Constitucional. Sentencia C-104 de 1993, M.P.: Alejandro Martínez Caballero.

8 "Como concepto, la constitucionalización no significa más que sólo una corrección de Derecho constitucional de las doctrinas particulares de Derecho administrativo. Quien quiere tomar en serio el concepto, debe estar preparado para examinar minuciosamente todas las relaciones sistemáticas. Los temas clásicos -legalidad, separación de poderes, formas de actuación, discrecionalidad, protección judicial efectiva, derecho de responsabilidad del Estado- no están superados, pero adquieren una dimensión diferente: ya no son solo dogmas, sino que forman una relación que debe asegurar un control jurídico efectivo de la administración. Se trata de un 'mandato doble del Derecho administrativo' que le[s] garantiza protección a los ciudadanos y a la administración, el cumplimiento eficaz de sus tareas. Para ello, es necesario utilizar la fuerza caracterizadora del sistema y el potencial de innovación de la Constitución. Esto es constitucionalización del Derecho administrativo": EBERHARD SCHMIDT-ASSMANN, "El concepto de la constitucionalización del 
Uno de los grandes cimientos de este código tiene precisamente como propósito que la Administración cambie de lógica frente al rol que desempeña frente a los derechos de las personas ${ }^{9}$, en la medida en que comprenda que el juez no es el encargado exclusivo de su protección -quien además debería hacerlo excepcionalmente-, sino que es aquella misma la llamada en primera instancia a abogar por su defensa ${ }^{10}$. En esa perspectiva, se busca que el Estado abandone su posición soberbia de "autoridad" -titular además de poderes exorbitantes-, frente a "sus administrados", para remplazarla por la de un gran servidor público, con personas titulares de derechos ${ }^{11}$.

En esa perspectiva, la búsqueda de armonización de la regulación en materia administrativa con la Constitución condujo, no solo a que la Carta Política dejara de considerarse simplemente como el texto-parámetro a partir del cual se desarrolla la legislación, sino también a que el derecho constitucional se convirtiera en el "marco"12 del derecho administrativo. Contexto en el que

derecho administrativo", La constitucionalización del derecho administrativo, Bogotá: Universidad Externado de Colombia, Alberto Montaña Plata y Andrés Fernando Ospina Garzón (eds.), 2014, p. 37.

9 Ello encuentra respaldo en la siguiente afirmación: "Con esta reforma, el gobierno nacional espera acabar con la lentitud, la congestión y parte de la corrupción en el tratamiento del procedimiento administrativo colombiano, lo que abre la puerta a una nueva generación de funcionarios, más informados y responsables, que esperan de parte del Estado una inversión considerable para poner en pleno funcionamiento la tan anhelada propuesta de lucha contra la arbitrariedad administrativa": Jaime Vidal Perdomo y Carlos Molina Betancur, Derecho administrativo, Bogotá: Legis, 2016, p. 566.

10 William Zambrano Cetina, "La protección de derechos en sede administrativa y la eficacia de los principios constitucionales de la función administrativa", en Instituciones del derecho administrativo en el nuevo Código. Una mirada a la luz de la Ley 1437 de 2011, Bogotá, 2012, p. 41. Disponible en: http://datateca.unad.edu.co/contenidos/109133/Documentos/Insituciones_del_derecho_administratrivo_en_el_nuevo_codigo.pdf [consultado el 30 de julio de 2016].

11 Augusto Hernández BecerRa, "El nuevo Código y la constitucionalización del derecho administrativo", en Instituciones del derecho administrativo en el nuevo Código. Una mirada a la luz de la Ley 1437 de 2011, cit., pp. 16 y 21.

12 "... el Derecho administrativo va más allá que el Derecho constitucional: en efecto, muchos temas del derecho administrativo - por ejemplo, acto administrativo, contrato administrativo, bienes públicos, función pública, responsabilidad administrativa, contencioso administrativo- son autónomos con respecto al Derecho constitucional; su noción y su régimen aparecieron independientemente de este y continúan a desarrollarse [sic] sin él. Estos temas no encuentran su fundamento en el Derecho constitucional [...] pero se puede decir que existe un marco constitucional del Derecho administrativo [...] Así, el Derecho administrativo de cada Estado puede insertarse en el Derecho constitucional que le es propio. Como lo precisó también el profesor Cassese, el Derecho administrativo varía de un país a otro. Esta variación resulta de las tradiciones nacionales. Estas se encuentran en el sistema constitucional que es la prolongación en el sistema administrativo. Cada sistema constitucional constituye el marco en el que se inserta el Derecho administrativo: él lo estructura y lo delimita, dejando la posibilidad de desarrollarse con soluciones que le son propias. [...] En consecuencia, si bien no hay verdaderamente una base constitucional 
precisamente se expide el Código de Procedimiento Administrativo y de lo Contencioso Administrativo (CPACA), que desde su artículo 1. ${ }^{\circ}$ consagra como fines la protección de los derechos y libertades de las personas, la primacía del interés general, la sujeción de las autoridades a la Constitución y el ordenamiento jurídico, y el funcionamiento eficiente y democrático de la Administración.

Es justamente al amparo de esas nuevas pautas que se dará vía, entre otras, a una novedosa figura en la materia, la extensión de la jurisprudencia de las sentencias de unificación, como herramienta idónea para garantizar, en sede administrativa, la efectiva y pronta protección de los derechos de los ciudadanos, en un plano de igualdad. La figura en Colombia nacería ligada a la constitucionalización del derecho administrativo, lo que significó, entre otras cosas, el reconocimiento de principios fundamentales (igualdad, seguridad jurídica, debido proceso), el reforzamiento de la coherencia y eficiencia del sistema, y la revaloración de la jurisprudencia como fuente del derecho.

\section{ANTECEDENTES DE LA FIGURA}

La extensión a terceros de los efectos de una sentencia es una figura procedente del derecho español, que inicialmente surge relacionada con la idea de reducir litigios ${ }^{13} \mathrm{y}$ posteriormente se entrelaza con la pretensión de garantizar el derecho a la igualdad.

En ese país se estableció desde el año de 1956, en la Ley Reguladora de la Jurisdicción Contencioso-Administrativa, artículo 86 apartado 2, cuando se consignó: "la sentencia que anulare el acto o la disposición producirá efectos entre las partes y respecto de las personas afectadas por los mismos".

Luego de este antecedente, la Ley Reguladora de la Jurisdicción Contenciosa Administrativa de 1998 entró a reglar el tema de manera más extensa. En el artículo 72 numeral 2 se dijo que la sentencia anulatoria de una disposición produciría efectos para todas las personas afectadas. Por otra parte, en el artículo 109 numeral 1 se estableció la posibilidad de que quienes no hubiesen sido parte en el proceso pudieran iniciar un procedimiento incidental de ejecución para que la sentencia les fuera aplicada ${ }^{14}$. Y finalmente, en el artículo $110^{[15]}$ se reguló la extensión de una sentencia a terceros en aquellos

que sirva de fundamento a la constitución del Derecho administrativo, hay en todo lado un marco constitucional del Derecho administrativo": PIeRre Devolvé, "La actualidad de la teoría de las bases constitucionales del derecho administrativo", en La constitucionalización del derecho administrativo, cit., pp. 58-59.

13 Eloísa Contín Trillo Figueroa, "Extensión de los efectos de la sentencia en la jurisdicción contencioso-administrativa", Revista Aragonesa de Administración Pública, n. ${ }^{\circ} 32,2008$, pp. 596-597.

14 Eduardo García de Enterría y Tomás Ramón Fernández, Curso de derecho administrativo, t. II, Pamplona: Thomson Reuters, 2015, pp. 677-678.

"Artículo 110. 
"pronunciamientos que contienen el reconocimiento o restablecimiento de una situación jurídica individualizada", "limitando la posibilidad a las materias tributarias y de personal al servicio de la Administración" (arts. 72.3 y 110). Es el caso de los llamados "actos de masa"16-17.

"1. En materia tributaria, de personal al servicio de la Administración pública y de unidad de mercado, los efectos de una sentencia firme que hubiera reconocido una situación jurídica individualizada a favor de una o varias personas podrán extenderse a otras, en ejecución de la sentencia, cuando concurran las siguientes circunstancias:

“a) Que los interesados se encuentren en idéntica situación jurídica que los favorecidos por el fallo.

"b) Que el juez o tribunal sentenciador fuera también competente, por razón del territorio, para conocer de sus pretensiones de reconocimiento de dicha situación individualizada.

"c) Que soliciten la extensión de los efectos de la sentencia en el plazo de un año desde la última notificación de ésta a quienes fueron parte en el proceso. Si se hubiere interpuesto recurso en interés de ley o de revisión, este plazo se contará desde la última notificación de la resolución que ponga fin a éste.

"2. La solicitud deberá dirigirse directamente al órgano jurisdiccional competente que hubiera dictado la resolución de la que se pretende que se extiendan los efectos.

"3. La petición al órgano jurisdiccional se formulará en escrito razonado al que deberá acompañarse el documento o documentos que acrediten la identidad de situaciones o la no concurrencia de alguna de las circunstancias del apartado 5 de este artículo.

"4. Antes de resolver, en los veinte días siguientes, el Secretario judicial recabará de la Administración los antecedentes que estime oportunos y, en todo caso, un informe detallado sobre la viabilidad de la extensión solicitada, poniendo de manifiesto el resultado de esas actuaciones a las partes para que aleguen por plazo común de cinco días, con emplazamiento en su caso de los interesados directamente afectados por los efectos de la extensión. Una vez evacuado el trámite, el Juez o Tribunal resolverá sin más por medio de auto, en el que no podrá reconocerse una situación jurídica distinta a la definida en la sentencia firme de que se trate.

"5. El incidente se desestimará, en todo caso, cuando concurra alguna de las siguientes circunstancias:

"a) Si existiera cosa juzgada.

"b) Cuando la doctrina determinante del fallo cuya extensión se postule fuere contraria a la jurisprudencia del Tribunal Supremo o a la doctrina sentada por los Tribunales Superiores de Justicia en el recurso a que se refiere el artículo 99.

"c) Si para el interesado se hubiere dictado resolución que, habiendo causado estado en vía administrativa, fuere consentida y firme por no haber promovido recurso contenciosoadministrativo.

"6. Si se encuentra pendiente un recurso de revisión o un recurso de casación en interés de la ley, quedará en suspenso la decisión del incidente hasta que se resuelva el citado recurso.

"7. El régimen de recurso del auto dictado se ajustará a las reglas generales previstas en el artículo $80^{\prime \prime}$

16 "La expresión 'actos de masa' es de la Exposición de Motivos de la LJ, § VI.3, se refiere al supuesto de que una misma disposición o resolución administrativa sea objeto de una multiplicidad (contados por miles en muchas ocasiones) de recursos. Por ejemplo: la regulación de una materia de personal, la clasificación de puesto de trabajo de un Ministerio, la alteración de los valores catastrales en una ciudad a efectos del Impuesto sobre Bienes Inmuebles, una determinada interpretación de una norma fiscal, que ha podido ser impuesta 
En 2003, mediante la Ley 20 de 9 de diciembre de 2013, se modificó el procedimiento, eliminando la petición previa ante la Administración, por considerarse inoficiosa, ya que la Administración negaba frecuentemente la petición de extensión ${ }^{18}$, y recientemente, por medio de la Ley 20 de 2013, se amplió la posibilidad de extender los efectos de una sentencia, procediendo ahora, además de en aquellos casos en materia tributaria y de personal al servicio de la Administración, frente a los asuntos relacionados con la "unidad de mercado"19.

Si bien en un comienzo se trataba de lograr el respeto, por parte de la Administración, del precedente judicial frente a aquellas personas que, sin haber exigido sus derechos en sede judicial, se encontraban en las mismas circunstancias de aquellos que habían sido parte de un proceso, posteriormente, como se puede apreciar en los argumentos con que se emitió la sentencia del Tribunal Constitucional español 10/98, lo que resalta como soporte del uso de la figura es el derecho fundamental a la igualdad ${ }^{20}$.

Por su parte, en Colombia, en las discusiones que se dieron al interior de la Comisión redactora del nuevo código y en los debates que se surtieron en el Congreso de la República acerca del mismo, hubo consenso en cuanto a la necesidad de consagrar un mecanismo orientado a la unificación de la jurisprudencia. Esto con el fin de descongestionar a la jurisdicción, en vista de que los asuntos serían decididos en sede administrativa, haciendo que la presencia del juez se diera solo respecto de controversias novedosas y que no hubieran sido decantadas previamente en la jurisprudencia.

Es de resaltar que en la exposición de motivos del proyecto de ley que daría como resultado el nuevo Código de Procedimiento Administrativo y de lo Contencioso Administrativo se dijo que la figura de la extensión de la sentencias de unificación del Consejo de Estado se orientaba al acatamiento de las decisiones judiciales como una manifestación del Estado social de derecho ${ }^{21}$, dotándolas de obligatoriedad para las autoridades públicas; por esto, cuando existiera un asunto con similitud de causa y efecto, se debería fallar de manera uniforme, de conformidad con la jurisprudencia ${ }^{22}$.

Así mismo, la Comisión redactora del código había referido que se debía procurar que llegara el menor número de procesos a la jurisdicción y que un

por una circular interna, los descuentos por jornadas perdidas en una huelga, convocatoria de un concurso de provisión de plazas, etc.": Eduardo García De EnTERría y Tomás Ramón FERNÁNDEZ, Curso de derecho administrativo, t. II, cit., p. 678.

17 Ibíd., p. 678.

18 Javier Tobo Rodrícuez, Extensión de la jurisprudencia del Consejo de Estado a terceros, Bogotá: Grupo Editorial Ibáñez, 2016, p. 30.

19 Ibíd., pp. 30-32.

20 Ibíd., pp. 30-32 y 34 .

21 Consejo de Estado, Sala de Consulta y de Servicio Civil, Las sentencias de unificación jurisprudencial y el mecanismo de extensión de la jurisprudencia, Bogotá, 2014, p. 334.

Ibíd., p. 25. 
mecanismo que lograra hacer extensivos los efectos de una decisión jurisprudencial con idénticos sustentos fácticos y jurídicos ayudaría no solo a lograr la descongestión sino también a brindar seguridad jurídica ${ }^{23}$.

Con todo, en el fondo, y de conformidad con los documentos mencionados, la intención de la implementación de la novedosa figura fue la de dotar de certeza, coherencia y seguridad jurídica al ordenamiento, procurando por la igualdad en la solución de las controversias que se presenten ante la Administración, y logrando de esta forma una protección efectiva de los derechos fundamentales de los ciudadanos, dotando a la jurisprudencia ${ }^{24}$ como el medio para alcanzar dichos fines.

\section{2. "EXTENSIÓN DE LA JURISPRUDENCIA"}

Para dimensionar esta novedosa figura desde sus diferentes aristas es necesario hacer un estudio compaginado del Código vigente en sus artículos 10, 102, 269 y 270. Los dos primeros artículos, referidos a la aplicación en sede administrativa de la figura, oficiosamente y a petición de parte, respectivamente, el artículo 269, que aborda el procedimiento judicial en su aplicación, y el artículo 270, donde se desarrolla el concepto de sentencia de unificación.

\subsection{Sede administrativa}

\subsubsection{Deber de las autoridades de aplicar uniformemente las normas y la jurisprudencia}

El artículo 10 en su primera parte consagra el deber de las autoridades de aplicar las disposiciones constitucionales, legales y reglamentarias de manera uniforme a asuntos que tengan los mismos supuestos fácticos y jurídicos. Mandato concordante con la Constitución, en la medida en que las autoridades solo pueden ejercer las funciones atribuidas por la Constitución y la ley (arts.

24 "Así, Hernández Becerra considera que en el nuevo código se expresa la llamada constitucionalización del derecho administrativo y observa que hay un cambio en la cultura jurídica nacional que otorga la posibilidad de atribuir a la jurisprudencia un rol importante en la orientación de la actuación de las autoridades administrativas y en las decisiones de los jueces. Para el exmiembro de la Comisión de la Reforma, la importancia de la jurisprudencia en este nuevo código es un tema transversal que comunica la primera parte con la segunda del Código". "Además, el CPACA propone en cinco artículos (10, 102, 269, $270,271)$ un práctico sistema de reglas que convierte a la jurisprudencia en guía segura para que el Estado dé a los ciudadanos un trato más igualitario y justo": INDIRA LATORRE GONZÁLEZ, El juez administrativo colombiano, iun factor influyente en el fortalecimiento del Estado social y constitucional de derecho?, Bogotá: Universidad del Rosario, 2015, p. 124. 
6 y 121), aunado a su deber de aplicar las mismas normas a aquellos que se encuentren en iguales circunstancia (art. 13).

En su segunda parte, aclara que con ese propósito deberán tener en cuenta las sentencias de unificación jurisprudencial del Consejo de Estado en las que se apliquen e interpreten. Con lo cual se reconoce importancia a la jurisprudencia emitida por aquel ente, en especial a las sentencias de ese tipo, bajo las cuales se procura cerrar discusiones y zanjar interpretaciones disconformes planteadas por las secciones o subsecciones, con miras a salvaguardar la igualdad y la seguridad jurídica.

De ello se desprende que, al momento de apartarse de dichas sentencias, y por tanto de la interpretación en ellas plasmada, se llegaría a desconocer indirectamente una norma jurídica. Pero, como lo estableció la Corte, precisamente se trata de un elemento vinculante, mas no obligatorio, pues su vinculatoriedad se entiende "en cuanto deben ser tomadas en consideración al momento de decidir conforme a las normas obligatorias ${ }^{\prime 25}$. En suma, lo que resulta de obligatorio cumplimiento es la interpretación legal comprendida en la jurisprudencia ${ }^{26}$.

De otro lado, aunque se mencionen específicamente las sentencias de unificación, la Corte definió que esa vinculatoriedad se extiende a la jurisprudencia de las demás cortes, y que se deberán observar con preferencia las decisiones por ella emitida, tratándose de la guardiana y máxima interprete de la Constitución.

\subsubsection{Petición de extensión de la jurisprudencia del Consejo de Estado por parte de las autoridades}

El artículo 102 establece que las autoridades deberán extender los efectos de una sentencia de unificación jurisprudencial dictada por el Consejo de Estado,

25 Andrés Ospina, "Comentario al artículo 10 del Código de Procedimiento Administrativo y de lo Contencioso Administrativo", Código de Procedimiento Administrativo y de lo Contencioso Administrativo, Ley 1437 de 2011. Comentado y concordado, Bogotá: Universidad Externado de Colombia, José Luis Benavides (coord.), 2013, pp. 79-80.

26 "Se pretende extender los efectos, mas no aplicar la sentencia, pues el código no admite que la sentencia sea por sí misma creadora de derecho y por lo tanto aplicable a un caso; lo que ocurre es que en ella se define una situación particular aplicando el derecho vigente, y lo que debe hacer la autoridad es resolver la petición del tercero de la misma forma como lo hizo la sentencia de unificación, siempre que se den todas las circunstancias descritas en la norma y que se comentan en seguida. La norma no exige que la condenada sea la misma entidad a la que se le pide la extensión de los efectos de la sentencia. Se advierte que puede haber casos en los que el derecho sea aplicable exclusivamente a determinados sujetos como por ejemplo, no puede pedirse que una ordenanza departamental se aplique junto con la sentencia de unificación que la interpreta a un departamento diferente de aquel en el que rige": EnriQue Arboleda Perdomo, Comentarios al Nuevo Código de Procedimiento Administrativo y de lo Contencioso Administrativo, Bogotá: Legis, 2014, p. 163. 
en la que se haya reconocido un derecho, siempre y cuando el peticionario acredite estar bajo los mismos supuestos fácticos y jurídicos, y la pretensión judicial no haya caducado (de ahí que sea un mecanismo para prevenir futuros litigios). Caso en el cual deberán decidir conforme a la Constitución, la ley, los reglamentos, y teniendo en cuenta la interpretación que de estas se haya hecho en la sentencia invocada con fines de extensión.

Luego pasa a exponer los requisitos que debe cumplir la petición de extensión, a saber: 1) contener una justificación razonada, donde quede claro que se encuentra bajo la misma situación de hecho y de derecho, 2) relacionar las pruebas con que cuente, y 3 ) aportar copia o referencia de la sentencia de unificación invocada.

En cuanto al procedimiento a seguir, se estableció que la autoridad deberá adoptar su decisión en los 30 días siguientes a la recepción de la petición, agregando que podrá negarla explicando razonadamente: 1) que existe imposibilidad de adoptarla (en realidad no se trata de una negativa) sin que se surta un periodo probatorio, sustentando la importancia del mismo y las pruebas que se utilizarán, con el fin de establecer que el demandante carece del derecho invocado; 2) que estima que la situación del solicitante es distinta a la de la sentencia invocada, y 3) que bajo su perspectiva las normas a aplicar no deben interpretarse en la forma indicada en la sentencia de unificación. Evento en el cual, si el peticionario acude al Consejo de Estado, este deberá pronunciarse frente a los argumentos planteados, con el fin de mantener o modificar su posición.

Más adelante se consagró que, si el acto reconoce el derecho, no procederá contra el mismo ningún recurso administrativo, sin perjuicio de un eventual control jurisdiccional ${ }_{i}$ y si, por el contrario, se niega total o parcialmente la petición, o si la autoridad guarda silencio, no se podrá cuestionar la decisión por ninguno de los dos medios antes mencionados frente a lo negado, pero el solicitante podrá acudir dentro de los 30 días siguientes ante el Consejo de Estado.

Finalmente se aclara que la solicitud suspende el término para la presentación de la demanda que procediere frente a la jurisdicción de lo contencioso administrativo, y se reanudará, una vez se cumpla el plazo de 30 días mencionado en el párrafo anterior, cuando el interesado decida no acudir ante dicho tribunal, o en caso contrario, una vez se surta el trámite dispuesto en el artículo 269.

\subsection{Sede JURISDicCIONAL}

\subsubsection{Petición de extensión de la jurisprudencia por parte del Consejo de Estado}

El artículo 269 establece que una vez negada la solicitud por la autoridad, o si guardó silencio, el interesado podrá acudir al Consejo de Estado mediante 
escrito razonado, acompañando copia de la actuación surtida ante la misma. Del escrito se dará traslado a la Administración "demanda" y a la Agencia Nacional de Defensa Jurídica del Estado por el término de 30 días para que aporten pruebas y, si es el caso, se opongan por las mismas razones por las que la autoridad negó la solicitud. Vencido este término se convocará a audiencia que deberá celebrarse en un plazo máximo de 15 días contados a partir de la notificación a las partes y en la que se escucharán los alegatos y se tomará la decisión. Si se estima procedente, el Consejo de Estado extenderá la sentencia invocada y reconocerá el derecho a que hubiere lugar.

Por último, el artículo 270 hace referencia a lo que debe entenderse por sentencias de unificación jurisprudencial, estableciendo que serán las que profiera o haya proferido el Consejo de Estado por importancia jurídica o trascendencia económica o social, o por necesidad de unificar o sentar jurisprudencia; igualmente, las proferidas al decidir los recursos extraordinarios y las relativas al mecanismo eventual de revisión.

\section{ANÁLISIS: ¿LA FIGURA ARMONIZA CON LA CONSTITUCIÓN?}

En comentarios anteriores hemos resaltado las ventajas de la consagración de esta institución como herramienta idónea, en líneas generales, para desarrollar y amparar postulados constitucionales como el de igualdad, seguridad jurídica, confianza legítima ${ }^{27}$ y eficiente y expedito acceso a la justicia. Ahora

27 Esta se entiende como "el instituto del derecho público, derivado de los postulados del Estado de Derecho, de la seguridad jurídica y de la equidad, que ampara a quienes de buena fe creyeron en la validez de los actos (de alcance particular o general, sean administrativos o legislativos), comportamientos, promesas, declaraciones o informes de las autoridades públicas, que sean jurídicamente relevantes y eficaces para configurarla, cuya anulación, modificación, revocatoria o derogación provoca un daño antijurídico en los afectados, erigiéndose, bajo la observancia de esos componentes, en un derecho subjetivo que puede invocar el administrado, y que consiste, en su aspecto práctico, en la limitación de los efectos de la anulación, de tratarse de un acto (de alcance individual o general) inválido en el reconocimiento del derecho a una indemnización de no ser ello posible; de tratarse de un acto o comportamiento válido, su continuidad o permanencia; en los supuestos de revocación o modificación de actos válidos o de derogación de actos normativos (administrativos o legislativos), en la posibilidad del reconocimiento del derecho a una indemnización": PEDRO J. CovieLlo, La protección de la confianza del administrado, Buenos Aires: LexisNexis, Abeledo-Perrot, 2004, 462. Así mismo, Valbuena Hernández, aunque concuerda con la definición, la complementa en los siguientes términos: "Coviello deja de advertir que no necesariamente la confianza legítima se predica de los administrados, pues como lo hemos visto en las demás definiciones, aquella también debe ser considerada desde la perspectiva del Estado, el cual, en determinadas circunstancias, puede obrar en calidad de confiante en su trato con los particulares, con otras entidades públicas e inclusive con otros estados y organismos internacionales. En segundo lugar, tampoco puede perderse de vista que el principio de protección de la confianza legítima no es un instituto que 
bien, para pasar al estudio constitucional de la misma no podemos olvidar que algunos de los artículos y expresiones de las normas estudiadas fueron objeto de control de constitucionalidad en las sentencias C-816 de 2011 y C-588 de 2012, siendo declarados exequibles.

En sentencia C-816 de 2011 se resolvió la demanda de constitucionalidad contra el artículo 102 inciso primero CPACA, por la presunta vulneración de los artículos 4, 230 y $241 \mathrm{CP}$. El demandante básicamente expuso dos razones: 1) que se estaría alterando el sistema de fuentes al establecer que las autoridades deben aplicar la jurisprudencia -la cual es criterio auxiliar-, y 2) que si la jurisprudencia a aplicar fuere exclusivamente la del Consejo de Estado se estaría socavando y dejando de lado la jurisprudencia emitida por la Corte Constitucional, especialmente en temas de derechos fundamentales. La Corte resolvió: 1) que el deber legal señalado no desconoce la preeminencia de la legislación como fuente del derecho, más aun teniendo en cuenta que la autoridad tiene la oportunidad de apartarse del precedente, y 2) que habría que entender la norma en el sentido de que las autoridades, al extender los efectos de las sentencias de unificación jurisprudencial del Consejo de Estado e interpretar las normas constitucionales, deben observar con preferencia los precedentes de la Corte Constitucional que interpreten las normas aplicables a la resolución de sus asuntos.

En sentencia C-588 de 2012 se resolvió la demanda de constitucionalidad contra los artículos 102 (parcial), 269 (parcial) y 270 (parcial) de la Ley 1437 de 2011, por la presunta vulneración del Preámbulo y los artículos 2, 4, 13, 29, 83, 93, 209 y 241 CP. El demandante básicamente expuso dos razones: 1) que el mecanismo de extensión de la jurisprudencia restringiría su aplicación a la sentencias de unificación de jurisprudencia del Consejo de Estado, esto en desconocimiento de: i) que el precedente es fijado de forma preferente por la Corte Constitucional ${ }_{i}$ ii) que son obligatorios los estándares internacionales establecidos por las cortes internacionales encargadas de interpretar los instrumentos sobre derechos humanos ratificados por Colombia; iii) que el precedente también puede estar fijado por sentencias de tutela dictadas por la Sala de Revisión o por la Sala Plena de la Corte Constitucional, o por las secciones de la Sala de lo Contencioso Administrativo del Consejo de Estado

pertenezca de manera exclusiva al campo del derecho público, como parece insinuarlo este autor argentino, pues es innegable, como lo hemos visto, que este principio también tiene cabida en otras ramas del derecho. Por otra parte, tampoco se puede soslayar que la confianza legítima puede gestarse igualmente en las decisiones judiciales [...]. Por último, consideramos que esta definición se concentra en el tema de los actos administrativos, dejando de lado aquellas situaciones de confianza originadas en hechos, omisiones y operaciones administrativas e inclusive en la apariencia": GabRiel ValbuEnA HernándeZ, La defraudación de la confianza legítima, Bogotá: Universidad Externado de Colombia, 2008, pp. 156-157. 
en sus autos o sentencias, lo que podría llegar a afectar el derecho de igualdad, la buena fe y el principio de seguridad jurídica $;$ y, 2) que se estaría autorizando a la Administración a no aplicar el ordenamiento jurídico vigente (el precedente constitucional y en materia contencioso administrativa, y los estándares internacionales), atentando contra los derechos de igualdad, debido proceso y la regla de legalidad.

La Corte resolvió: 1) declarar la cosa juzgada respecto de lo planteado frente al precedente de la Corte Constitucional, por ser un asunto ya decidido en la sentencia antes citada ${ }_{2}$ 2) subrayar que fue una decisión legislativa limitar el mecanismo de extensión de la jurisprudencia a las sentencias de unificación jurisprudencial proferidas por el Consejo de Estado. Agregando que no era necesario que se nombraran las reglas y estándares fijados por las cortes internacionales, teniendo en cuenta que su "criterio hermenéutico relevante" debían ser observado por las autoridades. Se dijo lo mismo respecto de las demás sentencias del Consejo de Estado, las cuales seguirían teniendo valor como precedente $; y, 3$ ) precisar que la facultad de controvertir la jurisprudencia cuya extensión se invoca solo puede ser excepcional y razonada.

\subsection{Aspectos CONTROVERSiales Del MECANISMO DE EXTENSIÓN DE LAS SENTENCIAS DE UNIFICACIÓN JURISPRUDENCIAL DEL CONSEJO DE ESTADO}

Una vez hecho este examen podemos pasar a analizar dos problemas ya tratados por estas sentencias. Esto porque, además de considerarlos como los inconvenientes principales de la figura, se convierten en el fundamento de nuestro desacuerdo con las posturas y argumentos expuestos por la Corte. Luego, abordaremos otros asuntos que a nuestro parecer resultan tangenciales, pero que son igualmente problemáticos. También se analizará la manera en que en ciertos casos el Consejo de Estado, en nuestro parecer, ha utilizado erróneamente la figura en comento, y finalizaremos con una conclusión general de todo lo aludido en el presente escrito.

1. ¿El hecho de que la Corte Constitucional haya admitido que las autoridades administrativas puedan apartarse del precedente jurisprudencial fijado por las altas cortes, reconociendo la autonomía de que gozan, repercute en la efectividad del mecanismo para procurar por la igualdad de trato jurídico, la seguridad jurídica y la confianza legítima al tenor de lo establecido en el artículos $1,2,4,13,83$ y $230 \mathrm{CP}$ ?

Para resolver este interrogante es importante resaltar que la jurisprudencia constitucional ha sido recurrente en establecer que las autoridades públicas se encuentran sometidas al imperio de la Constitución y la ley, y que como parte de esa imposición, así mismo deben aplicar el precedente jurispruden- 
cial fijado por la Corte Suprema de Justicia, el Consejo de Estado y la Corte Constitucional en sus respectivas jurisdicciones ${ }^{28}$.

En efecto, en muchos fallos de la Corte Constitucional ${ }^{29}$ se ha dicho que tal acatamiento de las decisiones que profieren las altas cortes tiene fundamento constitucional, establecido, entre otras disposiciones, en el artículo $230 \mathrm{CP}$. Ello es así, pues los operadores tanto judiciales como administrativos no están sometidos a la ley de manera puramente formal, sino que dentro del contenido de la misma se encuentra la interpretación de los máximos órganos judiciales.

Ahora bien, en lo que se refiere concretamente con las autoridades administrativas, la jurisprudencia constitucional ${ }^{30}$ ha sido constante en establecer que la aplicación del precedente jurisprudencial es estricta, pues a aquellas no les son aplicables las reglas de autonomía e independencia que sí se predican de las autoridades judiciales. Ello quiere decir que al momento de solucionar las controversias que se les presenten, la interpretación que deben realizar las autoridades administrativas sobre las normas aplicables al caso no puede derivar de su libre convicción, sino que debe estar siempre sometida a lo que hayan dispuesto al respecto las altas cortes en sus respectivas jurisdicciones.

Valga aclarar que el único escenario en el que adquieren un margen de interpretación más amplio se presenta cuando no existe un criterio uniforme en la jurisprudencia sobre un tema específico, pero al respecto la Corte Constitucional ha establecido que dicha facultad no es absoluta, sino que debe estar siempre enmarcada en los postulados de la Constitución y la ley ${ }^{31}$.

Todo lo dicho es lógico y encuentra su armonía con el ordenamiento jurídico, pues no sería viable equiparar la autonomía con que gozan las autoridades administrativas con la de las judiciales, pues estas últimas constitucionalmente están instituidas para impartir justicia en asuntos específicos. Ello cobra mayor relevancia si se tiene en cuenta que estas son las encargadas de revisar las decisiones de las primeras, cuando los ciudadanos hacen uso de los medios de control de nulidad o nulidad y restablecimiento del derecho.

A pesar de lo anterior, al consagrarse la figura de la extensión de la jurisprudencia el legislador dispuso que las autoridades administrativas pueden negar una solicitud que tenga tal fin, entre otras razones, exponiendo los motivos por los cuales consideran que las normas no se deben aplicar de la manera indicada en la sentencia de unificación (art. 3 CPACA). Como se dijo, tal disposición fue sujeta a control de constitucionalidad y la Corte, por medio de sentencia C-588 de 2012, la declaró exequible.

28 Corte Constitucional. Sentencia C-461 de 2013

29 Corte Constitucional. Sentencias C-836 de 2001, C-539 de 1999, T-079 de 1993, T-439 de 2000 .

30 Corte Constitucional. Sentencias T-566 de 1998, T-439 de 2000, SU-1122 de 2001, T-1 16 de 2004, C-589 de 2001.

31 Corte Constitucional. Sentencia T-116 de 2004. 
Al respecto, discrepamos totalmente de la disposición referida y de la sentencia que decidió sobre su exequibilidad. Por un lado, prácticamente se modificó la posición que había sentado la Corte en el sentido de decir que las autoridades administrativas no gozaban de autonomía para apartarse del precedente jurisprudencial fijado por las altas cortes. Nótese cómo, en la sentencia en comento, se hizo referencia a algo denominado "el apartamiento administrativo" para justificar que las autoridades sí pueden sustraerse de cumplir el precedente, pero en ningún momento se desarrolló tal concepto. Solo se hizo referencia a que el mismo había sido utilizado en la sentencia C-816 de 2011. Valga precisar que en esta última sentencia simplemente se dijo que la Ley 1437 de 2011 había consagrado la posibilidad de que las autoridades administrativas se apartaran del precedente jurisprudencial, y a ello le llamaron "apartamiento administrativo", sin hacer ningún análisis de fondo al respecto, pues tal disposición no fue objeto de estudio en la providencia.

De esa manera, la Corte se distanció parcialmente de lo que había establecido con anterioridad sobre la vinculatoriedad estricta del precedente para las autoridades administrativas y les otorgó la posibilidad de apartarse del mismo, utilizando además un argumento que consideramos precario, consistente en que aunque se niegue la solicitud de extensión de la jurisprudencia, el ciudadano afectado con tal decisión igualmente puede acudir ante el Consejo de Estado para que se examine el asunto.

Con ello entonces quedó establecido que las autoridades administrativas sí pueden apartarse del precedente fijado por las altas cortes, situación que no se armoniza con los postulados de un Estado social de derecho, pues el mecanismo de extensión de la jurisprudencia se estableció precisamente para que sirviera como instrumento para brindar armonía al ordenamiento jurídico, procurando garantizar el principio de igualdad, de confianza legítima y de seguridad jurídica, y de esta manera no estaría siendo realmente efectivo para el cumplimiento de dichos fines.

En nuestro sentir, por la manera en que quedó establecida la figura, se generará un margen de inseguridad jurídica mucho mayor, pues las autoridades administrativas en esa disconforme equiparación como "intérpretes autorizados" podrán decidir lo que a bien convengan según su convicción, lo cual, aunque se haga muy "clara y razonadamente", estaría poniendo en tela de juicio la función natural de las altas cortes. Estas, como sabemos, tienen la función de interpretar las normas en casos concretos y sentar criterios y conceptos lógicos, y hasta técnicos, elaborados a través del tiempo y bajo análisis complejos que solo ellas como tribunales de cierre pueden dimensionar.

A esto se suma el hecho de que se daría al traste con el diseño institucional, bajo el cual las autoridades están sometidas a la ley y a la Constitución, y a las interpretaciones que de estas se hagan, generando casi que un conflicto de "competencia funcional", y como consecuencia, desconociendo lo establecido en el artículo 209 CP, pues la función administrativa no se podrá desarrollar 
de manera eficiente, con economía y celeridad, y menos aún podrá garantizar la protección efectiva del derecho a la igualdad de los ciudadanos.

Lo anterior cobra mayor relevancia y resulta ser un tema crítico, si se tiene en cuenta que la cultura jurídica de la Administración, especialmente aquella de las autoridades administrativas, ha llevado a que se adopten decisiones sin sustento, olvidando el techo constitucional o interpretando la normatividad en desmedro de los ciudadanos, desatendiendo los postulados fundamentales aplicables a los casos sometidos a su conocimiento. Se estaría, pues, dotando de herramientas a quien en la mayoría de los casos ha demostrado no tener la capacidad de actuar bajo los parámetros de un Estado social de derecho; de ahí que la protección jurídica resulte generarse las más de las veces en sede judicial.

En últimas, gran parte de las solicitudes de extensión de la jurisprudencia terminarán llegando al Consejo de Estado para ser analizadas, debido a la renuencia que tendrán las autoridades administrativas a extender los efectos de una sentencia de unificación, lo cual ha llevado en la práctica a que muchas de ellas finalmente sean extendidas, contrario a otro de los fines por los cuales se consagró la figura: la descongestión en la jurisdicción.

2. ¿El hecho de que se hayan consagrado exclusivamente las sentencias de unificación del Consejo de Estado, como objeto del mecanismo de extensión de la jurisprudencia, y se hayan dejado de lado otras providencias de esa misma corporación, de las cortes internacionales o de la Corte Constitucional como órgano de cierre del sistema jurídico colombiano -que, no siendo de unificación, sientan precedentes claros en sus materias-, contrariaría la Constitución al desconocer los artículos 4, 13, 93, 209, 230, por cuanto se estaría habilitando a las autoridades y a los jueces a no acatar la ley -traducido ello en la inobservancia de los precedentes judiciales de las altas cortes y de las cortes internacionales-, al vulnerar los principios de igualdad, confianza legítima y seguridad jurídica?

Se ha enseñado como "verdad" aceptada que nuestro sistema jurídico corresponde al sistema del civil law, lo que le ha otorgado a la ley su posición como fuente principal de derecho, donde desde el poder legislativo y ejecutivo se da su elaboración, y desde el judicial se procede a su interpretación ${ }^{32}$. Se piensa pues que en ese ejercicio se apliquen normas preestablecidas, y por lo tanto, no se crearía derecho. Tanto así que desde el artículo 230 CP se

"Tradicionalmente se dice que el common law es un derecho jurisprudencial ${ }_{i}$ mientras que el derecho civil es un derecho de leyes, porque es hecho por el legislador. En efecto, el método inductivo, pragmático y casuístico del common law hace que un cúmulo de decisiones jurisprudenciales, en casos determinados, consolide una norma general de derecho, entre tanto, en el otro sistema -deductivo, cartesiano y dogmático- la jurisprudencia ayuda al entendimiento de la norma dictada por el legislador": MANuel FeRnANDO QuinCHE RAMíreZ, El precedente judicial y sus reglas, Bogotá: Universidad del Rosario, 2016, p. 7. 
estableció que los jueces en sus providencias solo están sometidos al imperio de la ley y que la jurisprudencia ocupará posición como criterio auxiliar en su actividad.

A pesar de ello, a lo largo de los años es innegable el papel preponderante que ha alcanzado la jurisprudencia como fuente de derecho, creando verdaderas normas jurídicas ${ }^{33}$, al entender que estas en su naturaleza ambigua muchas veces no pueden ser aplicadas en su sentido más general a un caso concreto, sin antes darles el sentido especial que las condiciones exijan, más aún, con la inclusión de conceptos como el de "precedente jurisprudencial", según el cual hay que tener en cuenta líneas jurisprudenciales reiteradas donde se haya solucionado de forma igual asuntos con supuestos fácticos iguales. Esto ha avanzado hasta el punto de que algunos juristas lleguen a asegurar que el derecho administrativo, por ejemplo, guarda mayor correspondencia con el sistema del common law, por trabajar diariamente con casos y reglas jurisprudenciales elaboradas al interior de la jurisdicción contencioso administrativa ${ }^{34}$.

Muestra de esta evolución se apreciaba ya desde el siglo pasado, pues la Corte Constitucional había reforzado esta tesis, aclarando que los precedentes cumplen una función trascendental, incluso en los sistemas de derecho legislado como el nuestro. Por ello, todos los jueces, y en especial el juez constitucional, tendrían que prestar especial atención a sus decisiones previas, esto por cuatro motivos fundamentales: 1) para salvaguardar la seguridad jurídica, conectado con lo anterior $; 2$ ) para proteger la libertad individual ante cambios

"El Derecho administrativo colombiano ha sido moldeado, en lo esencial, a golpe de leyes. Para citar sólo algunas de los siglos XX y XXI: Ley 27 de 1904, Ley 130 de 1913, Ley 167 de 1941, Decreto-Ley 01 de 1984, Decreto-Ley 2304 de 1989, Ley 489 de 1998 y Ley 1437 de 2011. A pesar de ese carácter esencialmente legislado de nuestro Derecho administrativo, la jurisprudencia no se ha resignado en ningún momento a cumplir la labor de ser tan solo 'la boca de la ley'. Por el contrario, la jurisprudencia administrativa nacional ha creado verdaderas normas jurídicas, algunas de ellas que se desprendían con gran creatividad de las interpretaciones posibles de artículos de una ley y otras que, incluso, surgieron directamente de la inspiración del juez, sin intermediación del legislador": Juan Carlos Henao, "La jurisdicción de lo contencioso administrativo: cien años creando derecho a partir de precedentes jurisprudenciales", 100 años de la jurisdicción de lo contencioso administrativo, Bogotá: Universidad Externado de Colombia, Alberto Montaña Plata y Andrés Fernando Ospina Garzón (eds.), 2014, p. 246.

34 Al respecto se ha afirmado: "Colombia tradicionalmente ha hecho parte del Sistema Continental, tal y como sucede con todos los países cuyas ciencias jurídicas están formadas sobre la base del Derecho Romano. Ahora bien, durante los últimos años, cierta parte de la doctrina colombiana discute la pertenencia del Régimen Colombiano a dicho sistema, así como la subsistencia del mismo, en razón al poder creador de derecho que parece atribuírsele[s] cada día con más fuerza a los jueces": BetTy Martínez Cárdenas, "Nueva perspectiva del sistema de derecho continental en Colombia", Ius et Praxis, año 17, n. ${ }^{\circ} 2$, 2011, pp. 25-52. Disponible en: http://www.scielo.cl/pdf/iusetp/v17n2/art03.pdf [consultado el 11 de octubre de 2016]. 
repentinos en los criterios de los jueces; 3) para garantizar la igualdad, y 4) para establecer una especie de control en la actividad judicial ${ }^{35}$.

Teniendo en cuenta lo dicho, a nuestro parecer, la Corte Constitucional se quedó corta al establecer sumariamente que las autoridades al extender los efectos de las sentencias de unificación jurisprudencial dictadas por el Consejo de Estado e interpretar las normas constitucionales base de sus decisiones debían observar con preferencia los precedentes de la Corte Constitucional. De un lado, pese a la declaratoria condicional de exequibilidad, se siguió excluyendo el precedente, esta vez, el establecido por el Consejo de Estado como órgano de cierre de la jurisdicción de lo contencioso administrativo, en aquellos asuntos que no son materia de sentencias de unificación; y de otro lado, bajo su misma lógica, se dio a entender que no es posible ir más allá y extender, como lo indica el mecanismo, los efectos de sentencias donde se haya sentado precedentes, tanto en materia constitucional como en lo contencioso administrativo.

A pesar de que el precedente jurisprudencial ha sido dotado de tal importancia, nos parece que en virtud del alcance dado a la figura de extensión de los efectos de las sentencias de unificación se está desconociendo el artículo $230 \mathrm{CP}$, casi al punto de anularlo. Bajo las nuevas limitaciones, solo podría ser observado el precedente contenido en las sentencias de unificación del Consejo de Estado, y el de la Corte Constitucional (este, solo para "ser tenido en cuenta"), y no aquellos que, no estando en las mismas, hayan establecido criterios y reglas para la solución de asuntos con los mismos supuestos fácticos y jurídicos. Por ello, nos encontramos de acuerdo con los argumentos esbozados por el demandante en la sentencia C-588 de 2012, al plantear que los precedentes también pueden estar contenidos en sentencias de tutela que profiera la Sala de Revisión o en autos de la Sala Plena en el caso de la Corte Constitucional, o en los autos y sentencias proferidos por las secciones del Consejo de Estado, y que al excluirlos, se estarían vulnerando los postulados constitucionales de igualdad y seguridad jurídica.

Aunque el rótulo de "sentencias de unificación" otorgue una percepción mayor de seguridad jurídica, no por ello se está autorizado para desconocer la existencia de precedentes ya lo suficientemente decantados, lo que haría caer en el absurdo de no reconocer derechos a quienes están en las mismas condiciones de quienes ya fueron favorecidos en fallos anteriores. Esta situación llevaría a la violación del principio de igualdad (art. $13 \mathrm{CP}$ ) en dos dimensiones: 1) como ya se dijo, se estaría autorizando el desconocimiento del precedente judicial frente a un caso ya dilucidado (trato desigual frente a casos idénticos), y 2) se estaría negando el acceso al mecanismo por el hecho de fundamentar las pretensiones en un "precedente" y no en una "sentencia 
de unificación", aunque de fondo se esté ante el mismo concepto y la misma lógica, bajo el argumento de que a estas últimas por su "importancia" se les da un tratamiento especial (trato desigual, en cuanto a la posibilidad de acceso al mecanismo).

A más de lo dicho, genera desconcierto el argumento estrella planteado por la Corte en sentencia C-588 de 2012 cuando dice que la forma en que fue configurado el mecanismo, para ser aplicado exclusivamente frente a ese tipo de sentencias, hace parte de la potestad de configuración normativa concedida al legislador por la Constitución (art. 150, ord. 2). Pero claro, evidentemente, bajo esta lógica falaz toda norma expedida por ese órgano sería elaborada bajo funciones constitucionalmente atribuidas que en ningún momento darían paso a poner en tela de juicio su legitimidad, cuando lo cierto es que no por el hecho de que se haga bajo la habilitación constitucional se sigue como consecuencia lógica que las normas sean constitucionales. En suma, la Corte en su "juicio de constitucionalidad" estudió la legitimidad funcional del Congreso para configurar leyes, y no la constitucionalidad de las normas, en sí mismas, como contenido, pretendiendo de esta forma sanear la omisión legislativa.

El otro cargo planteado por el demandante fue la posible vulneración del artículo $93 \mathrm{CP}$, referido a la no inclusión de los estándares fijados por las cortes internacionales encargadas de interpretar los instrumentos de derechos humanos ratificados por Colombia entre las providencias que pueden ser objeto del mecanismo de extensión de la jurisprudencia. Si bien prima facie estaríamos de acuerdo en reconocer su importancia en la interpretación del ordenamiento jurídico, entendemos los argumentos de la Corte en cuanto a que no es necesaria su consagración, ya que ese exceso legislativo resultaría redundante, sería tanto como hacer referencia en cada una de las normas expedidas por el legislativo al sometimiento y observancia de la Constitución, algo que no necesita ser reiterado por su naturaleza primigenia. Por lo cual podríamos comprender que la inclusión o no de las sentencias de la Corte Constitucional para fines de extensión sí correspondería al mundo de las posibilidades dentro las facultades de configuración de la ley, y más que eso, sí se prestaría para un análisis de constitucionalidad. Ahora bien, de esto no se desprende que por su carácter omnipresente no puedan ser materia de extensión, más aún si se trata del amparo del derecho a la igualdad y la confianza legítima.

El Consejo de Estado ha hecho varias precisiones frente a aquellas sentencias que tienen la virtualidad de ser objeto del mecanismo. A partir de una pregunta formulada por el Ministerio de Justicia y el Derecho frente a la expresión del artículo 270 del Código "las que profiera o haya proferido", explicó ${ }^{36}$ que en el concepto de "sentencias de unificación" están incluidas, además de aquellas que 
fueron expedidas con posterioridad a la ley, las que lo fueron con anterioridad con la misma función, aclarando que la labor de unificación jurisprudencial del Consejo de Estado no nació con la Ley 1437 de 2011. Siguiendo con su razonamiento, más adelante precisó que para acceder al mecanismo solo es necesario aportar una "sentencia de unificación jurisprudencial dictada por el Consejo de Estado", sin que se desprendan condiciones adicionales a las establecidas en el artículo 270, como que deban ser sentencias expedidas en sala plena o posteriores a la entrada en vigencia del Código.

Respecto a las sentencias expedidas por esta corporación que no son de unificación, se les dio valor como precedente, aclarando que por el hecho de no incluirse en esta categoría no pierden su carácter vinculante, reforzando lo dicho por la Corte Constitucional en sentencia 588 de 2012.

Sin embargo, vale la pena citar un aparte de un auto del Consejo de Estado expedido tiempo después y en el que parece plasmarse una nueva lectura sobre la discusión:

... por tanto los artículos 102 y 269 del Código de Procedimiento Administrativo y de lo Contencioso Administrativo deben ser interpretados, acorde con la Constitución Política, de manera tal que se entienda que el procedimiento de extensión de la jurisprudencia del Consejo de Estado es aplicable no solamente a las sentencias de unificación jurisprudencial del Consejo que allí se definen, sino también a todo precedente judicial adoptado por el Consejo de Estado, entendido como una sentencia en la cual esta Corporación haya adoptado una postura interpretativa determinada frente a un punto de derecho, sea que se haya desarrollado en una línea jurisprudencial o no, y siempre que se encuentre vigente y actualizada en tanto postura jurisprudencial del Consejo de Estado ${ }^{37}$.

Habrá entonces que ver cuál será la postura dominante en los años venideros.

\subsection{Problemas menores}

En la regulación del mecanismo de extensión de la jurisprudencia hay otras cuestiones $^{38}$ que suscitan dudas y que constituyen obstáculos para que el mismo sea aplicado de manera efectiva.

Nótese que en ninguna parte de las normas que lo consagran se estableció que para solicitar la extensión de una sentencia de unificación es requisito estar asistido por abogado. Ello ha generado serias dudas, pues en el Consejo de

37 Consejo de Estado, Sección Segunda. Auto del 9 de abril de 2014, rad. 11001-03-26-0002013-00096-00 (3918-13).

38 Tales aspectos también fueron abordados en el texto Consejo de Estado, Sala de Consulta y de Servicio Civil, Las sentencias de unificación jurisprudencial y el mecanismo de extensión de la jurisprudencia, Bogotá, 2014, pp. 473-480. 
Estado no existe unidad de criterio al respecto, ya que hay quienes piensan que para hacer uso de este mecanismo no se requiere estar asistido por un profesional del derecho ${ }^{39}$ como hay otros que consideran que $\mathbf{s i}^{40}$. En ese sentido es necesario que el legislador adopte una postura que ponga fin a esa disparidad de criterios o que el Consejo de Estado unifique su posición en sala plena ${ }^{41}$.

Además, tampoco se consagra la posibilidad de recurrir la decisión definitiva que adopte el Consejo de Estado sobre si extiende o no los efectos de una sentencia. Existe la duda de si respecto de la misma procede el recurso de reposición o el de súplica ${ }^{42}$. Al respecto nótese que al interior del Consejo de Estado ya se le ha dado el trámite de este último recurso ${ }^{43}$.

Otro aspecto importante que sin lugar a dudas afecta la efectividad del mecanismo tiene que ver con la manera en que se van a pagar las condenas favorables a los ciudadanos que eventualmente se logren con el uso del mecanismo ${ }^{44}$. Al respecto, en el Decreto 2170 de 2016, por medio del cual se liquidó el presupuesto general de la nación fijado en la Ley 1815 de 2016, simplemente se aludió al hecho de que cuando se extiendan los efectos de una sentencia de unificación proferida por el Consejo de Estado, la operación presupuestal será responsabilidad del jefe de cada órgano. Así entonces, ise podrá aplicar a cualquier rubro de la entidad? En nuestro concepto dicha regulación es ambigua y generará problemas para el reconocimiento de las sumas de dinero, y llevará a los ciudadanos a acudir ante las autoridades judiciales para dotar de un título que reconozca la condena.

Lo anterior supone que los ciudadanos se vean obligados a acudir ante los jueces para contar con un título que sí les permita gozar, económicamente hablando, de los derechos que les asisten, lo que implica que la justicia se congestionará aún más.

Todas estas cuestiones refuerzan la idea según la cual el mecanismo bajo estudio aún es precario para el logro de las finalidades para las cuales fue ins-

39 Al respecto ver la solicitud de extensión 11001-03-24-000-2012-00368-00, Sección Primera, C.P.: Guillermo Vargas Ayala, del 29 de abril de 2015, actor: Enrique Castillo Muñoz, demandado: Contraloría General de la República.

40 Sección Segunda. Auto de 19 de diciembre de 2013, rad. 11001032500020130130800 C.P.: Luis Rafael Vergara Quintero. También la solicitud 11001-03-27-000-2014-0002600 resuelta el 2 de marzo de 2015 por la Sección Cuarta, C.P.: Jorge Octavio Ramírez Ramírez.

41 Consejo de Estado, Sala de Consulta y de Servicio Civil, Las sentencias de unificación jurisprudencial y el mecanismo de extensión de la jurisprudencia, Bogotá, 2014, p. 473.

42 Ibíd., pp. 477-479.

43 Solicitud de extensión 11001-03-25-000-2013-01437-00 del 3 de abril de 2014, Sección Segunda, C.P.: Alfonso Vargas Rincón (e). El consejero que resolvió el recurso de súplica fue Gerardo Arenas Monsalve.

44 Consejo de Estado, Sala de Consulta y de Servicio Civil, Las sentencias de unificación jurisprudencial y el mecanismo de extensión de la jurisprudencia, cit., p. 480. 
tituido. Se requieren regulaciones adicionales para dotarlo de eficacia y para suplir todos los vacíos que se han comentado, para con ello lograr la protección efectiva de los derechos de los administrados.

A continuación se presentan casos tratados por el Consejo de Estado en los que indudablemente se nota la falta de apreciación de todo lo reseñado hasta ahora, haciendo evidente la precariedad del mecanismo para cumplir los fines constitucionales para los cuales fue instituido.

\section{ESTUDIO DE CASOS}

Primero. En una sentencia de tutela contra providencia judicial proferida por la Sección Quinta del Consejo de Estado (rad. 11001-03-15-000-2014-0131201, 2015) se analizó la legalidad de un fallo proferido por la Sección Tercera, Subsección "B" de esa misma corporación en la que se había negado la solicitud de extensión de los efectos de una sentencia de la Corte Constitucional (T-025 de 1994) en relación con el tema del desplazamiento forzado.

La Sección Quinta, al decidir, estableció que los efectos de las sentencias proferidas por la Corte Constitucional no son susceptibles de ser extendidos por medio del mecanismo que se estudia, aduciendo que el Consejo de Estado no tiene tal facultad, pues la Corte, en las sentencias de la C-634 de 2011, C-816 de 2011 y C-588 de 2012, en ningún momento lo habilitó para ello, precisando además que las sentencias de control abstracto de constitucionalidad (sentencias " $\mathrm{C}^{\prime \prime}$ ) contienen mandatos imperativos y en ningún momento necesitan de un mecanismo adicional -particularmente el de extensión de la jurisprudencia- para materializarlos.

Finalmente, en cuanto a los fallos de control concreto de constitucionalidad (sentencias " $\mathrm{T}$ " y "SU"), dijo que los mismos contienen efectos inter partes y la única habilitada para hacerlos extensivos a otros casos es la misma Corte Constitucional y no el Consejo de Estado.

Así, concluyó diciendo que las sentencias de la Corte Constitucional pueden servir para orientar al juez al momento de decidir una decisión sobre la extensión de los efectos de la jurisprudencia, pero el solicitante en todos los casos debe traer a colación una sentencia de unificación del Consejo de Estado, pues solo de esa manera se puede decidir de fondo el asunto.

Consideramos que la interpretación del Consejo de Estado al respecto va en contravía del sistema de fuentes de nuestro ordenamiento jurídico, así como de los postulados del Estado social de derecho.

Bien es sabido, tal y como se ha dicho a lo largo de este escrito, que la noción "imperio de la ley" establecida en el artículo $230 \mathrm{CP}$ hace referencia al ordenamiento jurídico en cuya cúspide se encuentra la Constitución, y dentro de ella también se hallan las interpretaciones que realiza la Corte sobre sus 
disposiciones, que en palabras de Alexy se denominan las "normas adscritas" de la misma ${ }^{45}$.

Así las cosas, negar que por medio del mecanismo de extensión de la jurisprudencia se obligue a que las autoridades administrativas acaten lo establecido en la Constitución -fijado en las normas adscritas que establece la Corte Constitucional-implica hacer nugatorios los postulados de la misma y negar su carácter supremo en el esquema de fuentes del derecho colombiano. Lo que está haciendo el Consejo de Estado al exigir que siempre deba citarse una sentencia de unificación proferida por dicha corporación es darle prevalencia a la ley sobre la Constitución, como si aún nos encontráramos en un Estado de derecho formalista y mecánico en la aplicación de los postulados del ordenamiento.

Salta a la vista además que la providencia en cuestión es contradictoria, pues en un primer momento afirma que la jurisprudencia de la Corte Constitucional tiene un carácter vinculante y ostenta una posición preferencial en el ordenamiento, y al final solo le reconoce un carácter "orientador" para decidir las solicitudes de extensión de la jurisprudencia.

Así, el Consejo de Estado olvida que hoy nos encontramos en el marco de un Estado social de derecho que procura por la satisfacción efectiva de las garantías y derechos establecidos en la Constitución, cuyo máximo intérprete es la Corte Constitucional, y que negar la aplicación de sus sentencias implica desconocer tal realidad, circunscribiéndose a una interpretación formalista que ya años atrás debió haber quedado superada.

No se entiende cómo, a pesar de existir pronunciamientos de la Corte Constitucional ${ }^{46}$ en los que ya dejó claro que las autoridades administrativas, al momento de decidir sobre solicitudes de extensión de la jurisprudencia, han de acatar de manera preferente su jurisprudencia, hoy en día ello se pase por alto y se exija con rigorismo que siempre debe presentarse una sentencia de unificación del Consejo de Estado, como si este fuera la instancia máxima que interpreta todo el ordenamiento jurídico.

De esta manera queda claro que el mecanismo no está siendo utilizado para lograr los fines para los cuales se instituyó. Negar la aplicación extensiva de las sentencias de la Corte Constitucional de ninguna forma contribuye a una protección efectiva de los derechos fundamentales, máxime cuando es la corporación que a diario discute los temas más sensibles sobre los mismos.

Por todo lo dicho, se hace necesario que el Consejo de Estado modifique su posición al respecto, teniendo claro en qué clase de modelo de Estado nos

46 Sentencias C-634 de 2011, C-816 de 2011 y C-588 de 2012 
encontramos, dejando atrás la aplicación mecánica del derecho e interpretando adecuadamente los fallos de control abstracto de constitucionalidad.

De todas maneras, al interior de dicha corporación hay juristas que interpretan debidamente el mecanismo de extensión de la jurisprudencia. Valga aclarar, como una luz de esperanza, que el consejero Danilo Rojas Betancourt salvó su voto en la sentencia cuestionada, aduciendo lo que aquí se expone. Esperemos que su posición pueda tener acogida y con ello se logre encaminar el enfoque de la figura que se estudia hacia una mirada garantista de los derechos, y en respeto del esquema de fuentes de nuestro ordenamiento jurídico.

Segundo. Otra situación similar se presentó en el asunto resuelto por el Consejo de Estado en auto de 15 de enero de 2014, con ponencia del consejero Jorge Octavio Ramírez. Los actores habían solicitado al Instituto Nacional de Vías (INVIAS) la extensión de los efectos de sentencias proferidas por la Corte Constitucional y el Consejo de Estado, sobre la pérdida de fuerza ejecutoria del acto administrativo y el pago de lo no debido, por creer encontrarse bajo las mismas condiciones fácticas y jurídicas, con ocasión del pago de la contribución por valorización por una obra. La entidad negó la solicitud, argumentando que no hubo pago de lo no debido, frente a algunos peticionarios, por presentación extemporánea de la reclamación y frente a los demás, por cuanto, aunque lo hicieron en tiempo, los dineros pagados habían entrado a hacer parte del erario público para el cumplimiento de los compromisos pactados en el convenio interadministrativo.

Los actores presentaron petición de extensión de los efectos de sentencias proferidas por varias secciones del Consejo de Estado y por la Corte Constitucional, petición que sin embargo fue rechazada por improcedente. Frente a las primeras, esta corporación argumentó que no cumplían con los requisitos para ser consideradas como de unificación y por tanto no les era aplicable el mecanismo. Se aseguró además que para hablar de sentencia de unificación jurisprudencial no bastaba con que hubiera sido emitida por la sala plena o por una de las secciones del Consejo de Estado, sino que debía cumplir con el artículo 271, el cual no existía para el momento en que estas habían sido expedidas. Frente a las segundas, la corporación aclaró que le mecanismo no estaba diseñado para extender sentencias emitidas por esa corporación, pero que en todo caso sí debían ser tenidas en cuenta al momento de decidir solicitudes de extensión de sentencias de unificación del Consejo de Estado claramente identificadas.

Además de los comentarios ya hechos frente al primer caso expuesto, hay que hablar acerca de ciertas especificidades. Nos parece que el Consejo de Estado está llevando al extremo la interpretación planteada sobre cuáles sentencias son susceptibles de extensión, hasta el punto, como en el caso concreto, de no referirse al contenido de una sentencia de tutela y una de constitucionalidad, por no haber invocado una de unificación del Consejo de Estado, como si estas fueran requisito habilitante para utilizar aquellas, asunto que se 
vuelve problemático al encontrarnos frente a una sentencia que examina la constitucionalidad de una norma.

Lo anterior ha sido recurrente al interior de la corporación, pues es notable que la Sección Segunda, Subsección "A"47, está siendo tan rigurosa y formalista que rechaza solicitudes de extensión de la jurisprudencia cuando se solicita la extensión de los efectos de sentencias de constitucionalidad, solo con el argumento de que el mecanismo está instituido para hacer ello aplicable exclusivamente respecto de sentencias de unificación del Consejo de Estado y no atiende que las primeras son de carácter obligatorio.

De otro lado, no es cierto que no pueden ser llamadas sentencias de unificación las no expedidas bajo la vigencia del artículo 271 de la Ley 1437 de 2011. El Consejo de Estado, Sala de Consulta y Servicio Civil, mediante auto de 10 de diciembre de 2013, consejero William Zambrano Cetina, en consulta absuelta al Ministerio de Justicia, estableció claramente que las sentencias proferidas con anterioridad al CPACA por la sala plena y las secciones del Consejo de Estado con el objeto de unificar jurisprudencia son sentencias de unificación jurisprudencial en los términos del artículo 270 CPACA.

\section{CONSIDERACIONES FINALES}

Así las cosas, de conformidad con lo reseñado a lo largo del presente escrito, es claro que si bien la intención del legislador fue la de instaurar una figura que favoreciera la igualdad, la seguridad jurídica y la confianza legítima, es notable que la manera en que ha sido abordada tanto por la Corte Constitucional como por el Consejo de Estado impide hacer efectivos dichos fines. Nos encontramos en la práctica ante un mecanismo que, tal y como está consagrado actualmente, no hará otra cosa distinta que generar un mayor desorden en el tráfico jurídico y congestionar la justicia, debido a que, como ya se dijo, aunque la figura sea utilizada adecuadamente, el respaldo presupuestal es precario y se requerirán títulos, llámense sentencias o tutelas, para sufragar los gastos que suponga el reconocimiento de derechos o prestaciones en uso de la misma.

Los problemas traídos a colación perdurarán mientras no se le dé un trato adecuado a la figura, permitiendose a los ciudadanos gozar de una protección efectiva de sus derechos en un plano de igualdad, lo que requiere una actuación por parte de las autoridades administrativas y por el Consejo de Estado

Al respecto ver Consejo de Estado, Sala de lo Contencioso Administrativo, Sección Segunda, Sub-sección "A". Sentencias de 3 de febrero de 2015, C.P.: Gustavo Eduardo Gómez Aranguren, rad. 11001-03-25-000-2014-01481-00, actor: Aura Leonor Cabra Garzón, demandado: Unidad Administrativa Especial de Gestión Pensional y Contribuciones Parafiscales de la Protección Social (UGPP); y de 3 de febrero de 2015, C.P.: Gustavo Eduardo Gómez Aranguren, rad. 11001-03-25-000-2014-00532-00, actor: Jorge Luis Pabón Apicella, demandado: Administradora Colombiana de Pensiones (Colpensiones). 
particularmente, que se acompase con dicha finalidad, reformulando la óptica rigurosa, mecánica y formalista con la que se han tratado las disposiciones que la consagran y yendo un poco más allá, en procurando del respeto de la persona humana como el eje central en un Estado social de derecho, para con ello dar cabal cumplimiento a los fines esenciales del Estado consagrados en el artículo 2 CP.

Inclusive, las críticas sentadas en el presente trabajo deben ayudar a tomar conciencia sobre la base de que en nuestro país actualmente nos encontramos en el tránsito hacia "la paz" como manifestación de la culminación del conflicto armado que hemos padecido, por lo que las ramas del poder público, particularmente la ejecutiva -la Administración-, han de superar los obstáculos reseñados ${ }^{48}$.

No sobra advertir además que la regulación del mecanismo es precaria y hace necesaria la presencia de disposiciones reglamentarias que precisen su alcance tanto procedimentalmente como materialmente, pues solo de esta manera se podrá superar la incertidumbre y la disparidad de criterios que se han generado al respecto.

\section{BIBLIOGRAFÍA}

Alexy, Robert. Teoría de los derechos fundamentales, Madrid: Centro de Estudios Constitucionales, 1997.

Arboleda Perdomo, Enrique. Comentarios al Nuevo Código de Procedimiento Administrativo y de lo Contencioso Administrativo, Bogotá: Legis, 2014.

Consejo de Estado, Sala de Consulta y de Servicio Civil. Las sentencias de unificación jurisprudencial y el mecanismo de extensión de la jurisprudencia, Bogotá, 2014.

Consejo de Estado, Sala de Consulta y de Servicio Civil. Memorias de la Ley 1437 de 2011, Bogotá, 2014.

Consejo de Estado. Instituciones del derecho administrativo en el nuevo Código. Una mirada a la luz de la Ley 1437 de 2011, Bogotá, 2012.

Coviello, Pedro J. La protección de la confianza del administrado, Buenos Aires: LexisNexis, Abeledo-Perrot, 2004

48 "Dadas las premisas, por respeto al rigor científico el discurso debe agotar ciertas etapas necesarias: la primera es aquella que he definido como la 'juridificación' del concepto de buena administración, la segunda es la afirmación de que la buena administración es un presupuesto ineludible para la paz, y la tercera tiene una naturaleza crítica: los senderos de la buena administración están llenos de riesgos (a menudo el fin es traicionado por los medios) y no pueden ser afrontados sin recursos": MARCO DuGaTO, "Buena administración para la paz", La constitucionalización del derecho administrativo, t. II, cit., p. 335. 
Latorre González, Indira. El juez administrativo colombiano, cun factor influyente en el fortalecimiento del Estado social y constitucional del derecho?, Bogotá: Universidad del Rosario, 2015.

Martínez Cárdenas, Betty. "Nueva perspectiva del sistema de derecho continental en Colombia", Ius et Praxis, año 17, n. ${ }^{\circ}$ 2, 2011.

Montaña, Alberto y Ospina, Andrés (eds.). 100 años de la jurisdicción de lo contencioso administrativo, "Justificación, retos y aporte al derecho administrativo", XIV Jornadas de Derecho Administrativo, Bogotá: Universidad Externado de Colombia, 2014.

Montaña, Alberto y Ospina, Andrés et al. (eds.). La constitucionalización del derecho administrativo, XV Jornadas Internacionales de Derecho Administrativo, Bogotá: Universidad Externado de Colombia, 2014.

Montaña, Alberto y Ospina, Andrés et al. (eds.). La constitucionalización del derecho administrativo, El derecho administrativo para la paz, Bogotá: Universidad Externado de Colombia, 2016.

Ospina, Andrés. "Comentario al artículo 10 del Código de Procedimiento administrativo y de lo contencioso administrativo", en Código de Procedimiento Administrativo y de lo Contencioso Administrativo, Ley 1437 de 2011. Comentado y concordado, Bogotá: Universidad Externado de Colombia, José Luis BenAvides (coord.), 2013.

Ospina Fernández, Andrés Fernando. "Presentación: la responsabilidad del Estado y el Estado de derecho en Colombia", en La responsabilidad extracontractual del Estado, Bogotá: Universidad Externado de Colombia, Juan Carlos HenaO y Andrés Fernando Ospina Garzón (eds.), 2015.

Quinche Ramírez, Manuel Fernando. El precedente judicial y sus reglas, Bogotá: Universidad del Rosario, 2016.

Tobo Rodríguez, Javier. Extensión de la jurisprudencia del Consejo de Estado a terceros, Bogotá: Grupo Editorial Ibáñez, 2016

Valbuena Hernández, Gabriel. La defraudación de la confianza legítima, Bogotá: Universidad Externado de Colombia, 2008.

Velásquez Turbay, Camilo. Derecho constitucional, Bogotá: Universidad Externado de Colombia, 2004.

Velásquez Gómez, Jean Paul. La constitucionalización del juez administrativo en Colombia, Bogotá: Grupo Editorial Ibáñez, 2004.

Vidal Perdomo, Jaime y Molina Betancur, Carlos, Derecho administrativo, Bogotá: Legis, 2016. 
Younes Moreno, Diego. Derecho constitucional colombiano, Bogotá: Legis, 2014.

\section{JURISPRUDENCIA}

Consejo de Estado, Sala de Consulta y Servicio Civil. 10 de diciembre de 2013, C.P.: William Zambrano Cetina, rad. 11001-03-06-000-2013-00502-00.

Consejo de Estado, Sala de lo Contencioso Administrativo, Sección Cuarta. Auto de 15 de enero de 2014, C.P.: Jorge Octavio Ramírez, rad. 2013-00017.

Consejo de Estado, Sala de lo Contencioso Administrativo, Sección Segunda. Auto del 9 de abril de 2014, C.P.: Gustavo Gómez Aranguren, rad. 11001-03-25-0002013-01528-00 (3918-13)

Consejo de Estado, Sala de lo Contencioso Administrativo, Sección Quinta. Sentencia de 5 de febrero de 2015, C.P.: Lucy Jeannette Bermúdezad. 11001-03-15-0002014-01312-01 (acción de tutela).

Corte Constitucional. Sentencia C-104 de 1993.

Corte Constitucional. Sentencia T-025 de 1994.

Corte Constitucional. Sentencia SU-047 de 1999.

Corte Constitucional. Sentencia T-116 de 2004.

Corte Constitucional. Sentencia C-816 de 2011.

Corte Constitucional. Sentencia C-588 de 2012.

Corte Constitucional. Sentencia C-461 de 2013. 